Original article

Received: 19 April 2017 / Accepted: 26 May 2017

\title{
REMOTE SENSING TO ESTIMATE SATURATION DIFFERENCES OF CHOSEN BUILDING MATERIALS USING TERRESTRIAL LASER SCANNER
}

\author{
Czesław Suchocki ${ }^{1}$, Jacek Katzer ${ }^{1}$, Arkadiusz Panuś ${ }^{2}$ \\ 1) Koszalin University of Technology, \\ Faculty of Civil Engineering Environmental and Geodetic Sciences \\ 2) University of Warmia and Mazury in Olsztyn \\ Faculty of Geodesy, Geospatial and Civil Engineering
}

\begin{abstract}
Terrestrial Laser Scanner (TLS) method which is commonly used for geodetic applications has a great potential to be successfully harnessed for multiple civil engineering applications. One of the most promising uses of TLS in construction industry is remote sensing of saturation of building materials. A research programme was prepared in order to prove that harnessing TLS for such an application is viable. Results presented in the current paper are a part of a much larger research programme focused on harnessing TLS for remote sensing of saturation of building materials. The paper describes results of the tests conducted with an impulse scanner Leica C-10. Tests took place both indoors (in a stable lab conditions) and outdoors (in a real environment). There were scanned specimens of the most popular building materials in Europe. Tested specimens were dried and saturated (including capillary rising moisture). One of the tests was performed over a period of 95 hours. Basically, a concrete specimen was scanned during its setting and hardening. It was proven that absorption of a laser signal is influenced by setting and hardening of concrete. Outdoor tests were based on scanning real buildings with partially saturated facades. The saturation assessment was based on differences of values of intensity. The concept proved to be feasible and technically realistic.
\end{abstract}

Keywords: TLS, intensity, saturation, building materials

\section{Introduction}

Terrestrial Laser Scanning (TLS) is used by engineers in geodesy and civil engineering to acquire information about geometry of objects and spacing of smaller details on their surfaces. TLS is successfully utilized for surveying and technical diagnostics of structures and buildings. The most common TLS applications are associated with 
measurements of: geotechnical displacements, roads and motorways, archaeological sites and surveying of heritage buildings (Suchocki, 2009; Suchocki \& Wasilewski, 2008; Szulwic et al., 2016; Engström \& Johansson, 2009; Park and Lee, 2007; Mill et al., 2011, Oreni et al., 2014). Apart from basic 3-D co-ordinates, TLS gets information about quantity of returning laser beam summarized in one parameter called intensity. A type of scanned material significantly influences the power of the returning laser signal. It was proven, by multiple researchers (Bucksch et al., 2007; Voegtle et al., 2008), that a colour and roughness of a scanned surface are the key factors responsible for absorption and dispersion of the laser signal. Authors believe, that water saturation of building materials may also influence the quantity of the returning laser signal. Water is characterized by high absorption coefficient of a laser signal (Tan et al., 2016), thus different water saturation states of scanned materials should influence the properties of a returning laser signal. Changes in water saturation of a building material should result in changes of intensity registered by TLS. It should be possible to assess (apart from ordinary 3-D co-ordinates of a scanned object) water saturation and changes in water saturation of a given structural element. Such knowledge would be very useful especially during structural safety checks of old and historic buildings which are prone to being saturated due to lack of proper maintenance, deterioration of insulating materials, newly erected extensions and badly conducted restorations. Some attempts of harnessing intensity as a parameter identifying properties of a scanned material have been already done (e.g. remote diagnostics of a concrete dam (Zaczek-Peplinska, 2012; Zygmunt \& Biłka, 2014)). Authors decided to conduct a research programme which would prove the feasibility of TLS for remote sensing of water saturation of building materials. It was decided that research programme would cover testing different building materials in a different water saturation state.

\section{Theoretical background}

General relation between power of a transmitted and received signal by TLS is described by the following equation (Sabatini \& Richardson, 2010):

$$
P_{R}=\frac{P_{T} \sigma D^{4}}{16 R^{4} \lambda^{2} K_{a}^{2}} \eta_{A t m} \eta_{S y s}
$$

$$
\begin{array}{cl}
\text { where: } & \\
P_{R} & - \text { power of a received signal }(\mathrm{W}), \\
P_{T} & - \text { power of a transmitter }(\mathrm{W}), \\
R & - \text { range from a TLS to a target }(\mathrm{m}), \\
\sigma & - \text { effective target cross section }\left(\mathrm{m}^{2}\right), \\
\lambda & - \text { wavelength }(\mathrm{m}), \\
\mathrm{D} & - \text { aperture diameter }(\mathrm{m}) \\
\eta_{A t m} & - \text { atmospheric transmission factor, } \\
\eta_{S y s} & - \text { system transmission factor, } \\
\mathrm{K}_{\mathrm{a}} & - \text { aperture illumination constant, } \\
\alpha & - \text { angle of incidence }(\mathrm{g}), \\
\rho & - \text { reflectance of a material. }
\end{array}
$$


The equation (1) is usually used for LIDAR applications. In case of TLS applications, the equation comes in a simpler form (2). In this equation it is assumed that the surface of a target is rough (Lambertian surface) and it is always larger than the area of a laser spot (Pfeifer et al., 2008).

$$
P_{R}=\frac{\pi P_{T} \rho \cos \alpha}{4 R^{2}} \eta_{A t m} \eta_{S y s}
$$

The power of a received signal by TLS depends on multiple factors (see eq. 2). One can divide these factors into two groups: factors which are constant during a measurement and factors which are changeable during the measurement. Power of a transmitter should be recognized as a constant factor, because during any single measurement the transmitter works with the same power. System transmission factors are unknown for an average user of TLS. They are associated with technical specification of a given scanner (e.g. a type of a rangefinder - an impulse or phase, laser wavelength, sensitivity of a detector etc.). The system factors are constant during a measurement. There are also weather factors which can influence the quantity of the received laser signal. In case of measurements conducted indoors, in a stable lab conditions (temperature, light and air humidity) atmospheric transmission factor should be considered as constant, too. One should remember, that measurements conducted outdoors are usually very quick. In a very short period of time, when the measurement takes place the weather conditions do not significantly change. These possible, small changes in weather condition do not have noticeable influence on achieved results, thus they are very often omitted in further signal analysis (Tan \& Cheng, 2016).

The amount of energy emitted by a scanner, reflected and received back is influenced by the angle of a laser beam hitting an object and range between TLS and scanned object. This phenomenon was described by multiple researchers (Blaskow \& Schneider, 2014; Kaasalainen et al., 2011; Tan \& Cheng, 2016; Kukko et al., 2008; Pfeifer et al., 2008; Van Ree, 2006). It is important to remember that when scanning large civil engineering structures values of range $(R)$ and angle of a laser beam hitting an object $(\alpha)$ vary significantly. During the data processing it is possible to eliminate the influence of these factors on the value of achieved intensity (for each observed areas) through data standardization. The process of data standardization is thoroughly described in literature (Sasidharan, 2016; Kaasalainen et al., 2011; Blaskow \& Schneider, 2014; Tan \& Cheng, 2016).

The last factor which influences the power of the received signal is reflective characteristics of the scanned surface. Colour and roughness of the scanned surface are the key parameters defining reflective characteristics of a given surface. In authors' opinion reflective characteristics is also significantly influenced by water saturation (Suchocki \& Katzer, 2016). In some cases, when colour of the scanned surface is homogenised and its roughness uniformed water saturation may be the only factor influencing the registered values of the intensity, which is directly associated with reflectance of a material and can be expressed as follows:

where:

$$
\text { Intensity }=\rho_{1} \cdot C_{1} \cdot C_{2} \text {, }
$$

$\rho_{1}$ - reflectance of a material (saturation dependent)

$C_{1}=\pi P_{T} \eta_{A t m} \eta_{\text {Sys }}-$ unknown but constant parameter for a specific scanner

$C_{2}=\frac{\cos \alpha}{4 R^{2}}-$ changeable parameter which can be eliminated by data standardization 


\section{Conducted research and achieved results}

The research programme was divided into four work-packages. Work-package no. 1 covered tests conducted using impulse TLS scanner VZ-400 (by Riegl). This scanner is based on a narrow infrared (wavelength from $700 \mathrm{~nm}$ to $1000 \mathrm{~nm}$ ) laser beam. Laser beam divergence is equal to $0.35 \mathrm{~mm}$ and its pulse repetition varies from $100 \mathrm{kHz}$ to $300 \mathrm{kHz}$. Effective measurement rate is from 42,000 meas/s to 122,000 meas/s. Measure range is from $1.5 \mathrm{~m}$ to $600 \mathrm{~m}$. Building materials which were remotely scanned were: ordinary concrete, cellular concrete, red ceramic and silica. Specimens were in a form of cubes and prisms. There were prepared three types of specimens: oven dry specimens, specimens saturated only by air humidity and fully saturated specimens. The specimens were remotely scanned from three distances $(27 \mathrm{~m}, 17 \mathrm{~m}$ and $7 \mathrm{~m}$ ) (Suchocki \& Katzer, 2016).

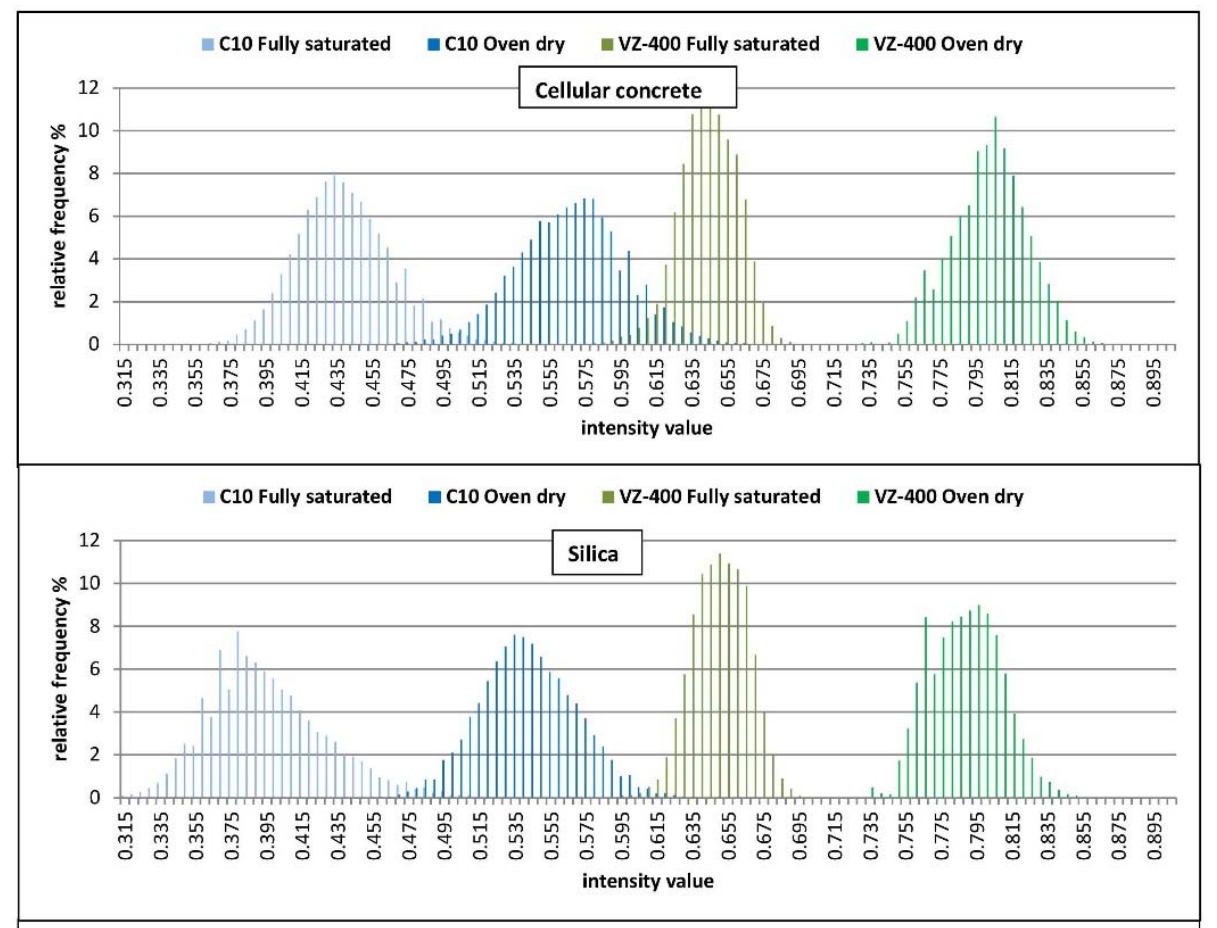

Fig.1. Intensity for materials in two states of water saturation (Suchocki \& Katzer, 2016)

Work-package no. 2 covered tests conducted using an impulse TLS scanner ScanStation C10 (by Leica). This scanner is characterized by visible green laser (wavelength $=532 \mathrm{~nm}$ ). The minimum measure range is equal to $0.1 \mathrm{~m}$. Scan resolution for the range from $0 \mathrm{~m}$ to $50 \mathrm{~m}$ is equal to $4.5 \mathrm{~mm}$ and $7.0 \mathrm{~mm}$ for $\mathrm{FWHH}$ based and Gaussian-based measurements respectively. The scanner is capable of conducting high speed scanning at rate of $50,000 \mathrm{pts} / \mathrm{sec}$. There were scanned the same specimens in the same conditions as in work-package no. 1. In Fig. 1, values of intensity registered by both scanners for materials in two states of water saturation are presented.

Work-package no. 3 consisted of scanning ordinary concrete during first the 95 hours of curing (setting and hardening). The surface of the specimen was in a form of a slab $(0.3 \mathrm{~m} \cdot 0.3 \mathrm{~m} \cdot 0.05 \mathrm{~m})$. A fresh concrete mix was poured into a mould and the surface of the specimen was scanned by TLS in time intervals from $0 \mathrm{~h}$ to $95 \mathrm{~h}(0,1$, $2,4,10,22,27,46,52,54,71,77,95)$ from the fixed distance of $7 \mathrm{~m}(R=$ constant $)$ in 
lab conditions. Taking into account the size of the specimen and its range from the TLS, changes of the angle of incidence $(\alpha)$ did not influence the value of intensity $\left(C_{2}\right.$ = constant, see Eq. 3). The only factor which was significantly changing, alongside time of curing, was reflective characteristics of a scanned concrete surface. During the process of setting and hardening of the concrete the reflective characteristics of its surface was influenced by amount of free water. At the beginning the surface of the specimen was "fully saturated". Over the passing time, fresh concrete mix was setting (change from a fluid to a rigid state) and hardening (gain of strength). The setting usually starts after $1-2$ hours after adding water to cement. The hardening usually starts after $8-10$ hours after adding water to the cement. Scanning conducted after 0,1 and 2 hours of curing represent results for liquid concrete mix, scanning conducted after 4 hours represents results in a transition state between liquid and rigid state of the concrete. Scanning conducted after 10 hours and onward represents results for rigid state of concrete. During the complex chemical process of setting and hardening of concrete water saturation, roughness and colour are changing. All these factors significantly influence the quantity of the received laser signal.

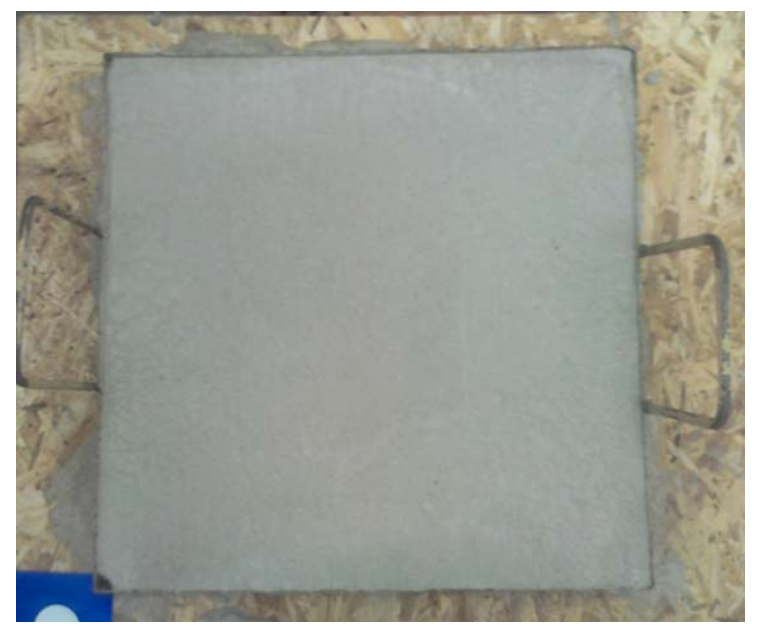

Fig. 2. Tested concrete specimen - during setting and hardening

In Fig. 3, a cloud of results achieved during first, eighth and thirteenth scanning at the time of $0 \mathrm{~h}, 46 \mathrm{~h}$ and $95 \mathrm{~h}$ respectively is presented. The images were created using artificial colours. Full histograms of the registered intensity are presented in Fig. 4, where the relative frequency of results was used as a scale for vertical axis and values of intensity without denomination were scaled on the horizontal axis.

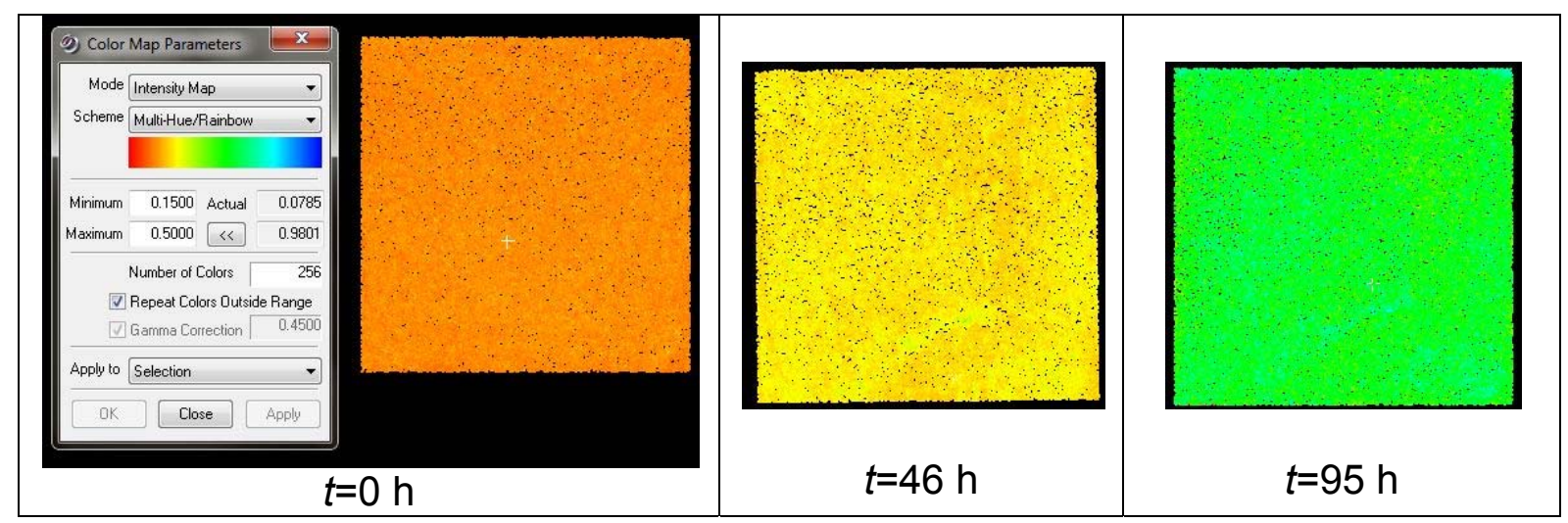

Fig.3. Images created by TLS (using artificial colours) of a concrete specimen after $0 \mathrm{~h}, 46 \mathrm{~h}$ and $95 \mathrm{~h}$ of curing 
There are clearly visible differences in values of intensity between fresh concrete mix (0h) and hardening concrete $(46 \mathrm{~h}, 95 \mathrm{~h})$. In case of fresh concrete mix, results form one dense population with a clear peak and relative frequency reaching over $41 \%$. The population of results for $46 \mathrm{~h}$ of curing is also characterized by a clear peak but relative frequency reaches only $27 \%$. In case of results achieved after $95 \mathrm{~h}$ relative frequency reaches values of $10 \%$.

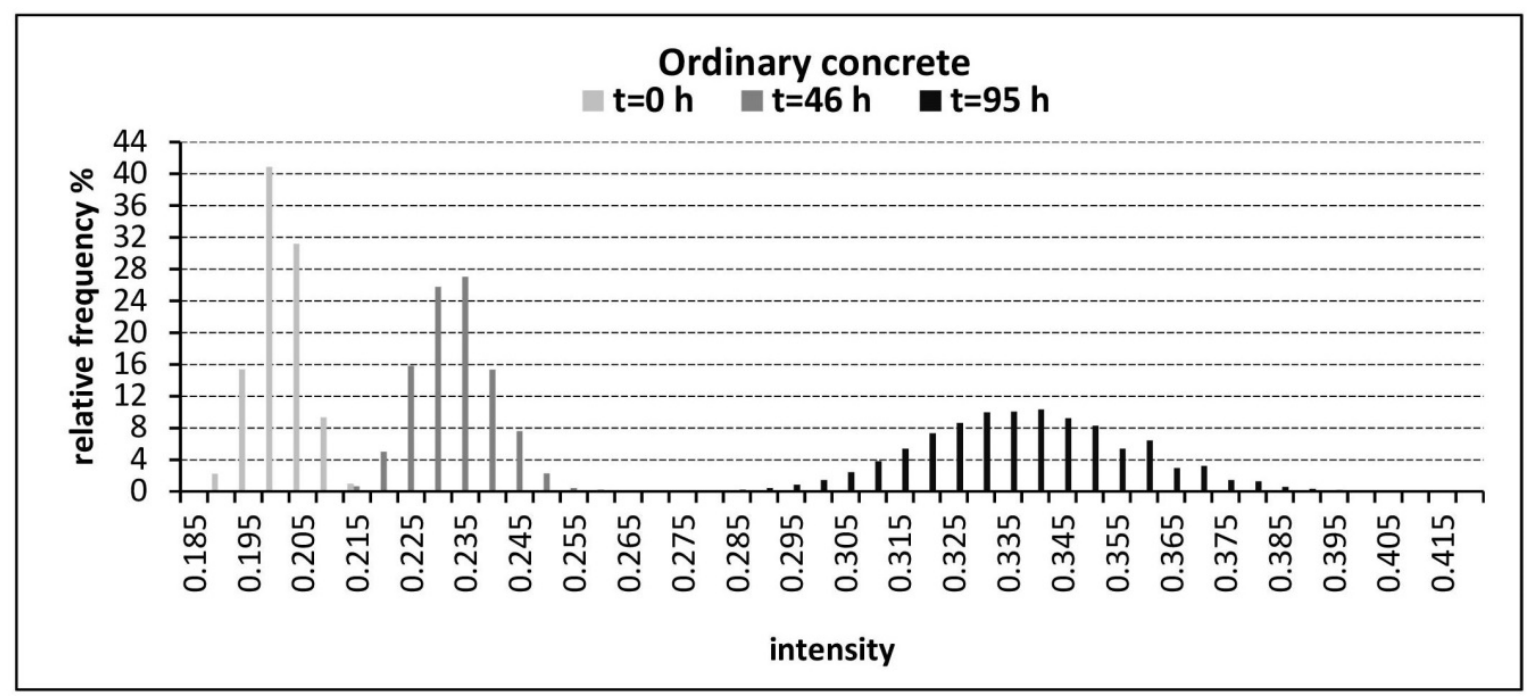

Fig. 4. Intensity registered for ordinary concrete after $0 \mathrm{~h}, 46 \mathrm{~h}$ and $95 \mathrm{~h}$ of curing

Table 1. Statistical description of intensity registered for concrete during curing

\begin{tabular}{|c|c|c|c|c|c|c|c|c|c|c|c|c|c|}
\hline time $[\mathrm{h}]$ & 0 & 1 & 2 & 4 & 10 & 22 & 27 & 46 & 52 & 54 & 71 & 77 & 95 \\
\hline minimum & 0.182 & 0.179 & 0.180 & 0.178 & 0.181 & 0.187 & 0.193 & 0.207 & 0.214 & 0.222 & 0.231 & 0.246 & 0.264 \\
\hline maximum & 0.220 & 0.218 & 0.218 & 0.218 & 0.228 & 0.241 & 0.248 & 0.301 & 0.303 & 0.325 & 0.376 & 0.398 & 0.434 \\
\hline average & $\mathbf{0 . 1 9 8}$ & $\mathbf{0 . 1 9 7}$ & $\mathbf{0 . 1 9 7}$ & $\mathbf{0 . 1 9 7}$ & $\mathbf{0 . 2 0 0}$ & $\mathbf{0 . 2 0 7}$ & $\mathbf{0 . 2 1 4}$ & $\mathbf{0 . 2 3 1}$ & $\mathbf{0 . 2 3 8}$ & $\mathbf{0 . 2 4 7}$ & $\mathbf{0 . 2 7 3}$ & $\mathbf{0 . 3 0 7}$ & $\mathbf{0 . 3 3 6}$ \\
\hline range & 0.038 & 0.039 & 0.038 & 0.040 & 0.048 & 0.054 & 0.055 & 0.094 & 0.089 & 0.103 & 0.145 & 0.152 & 0.170 \\
\hline median & 0.198 & 0.197 & 0.197 & 0.197 & 0.200 & 0.207 & 0.214 & 0.230 & 0.238 & 0.245 & 0.271 & 0.307 & 0.335 \\
\hline mode & 0.199 & 0.196 & 0.196 & 0.196 & 0.199 & 0.207 & 0.213 & 0.228 & 0.237 & 0.245 & 0.270 & 0.306 & 0.336 \\
\hline
\end{tabular}

The Statistical description of all thirteen measurements of concrete during curing is summarized in Tab. 1. It should be noted that alongside passing time of curing average value of intensity is getting larger and larger, hence laser beam absorption coefficient is getting smaller and smaller. While analysing minimum values, maximum values and stretch of values of intensity, one can discover that the longer curing time, the more varied are the values of intensity. In majority of cases values of average, median and mode are similar. It proves that intensity is characterized by symmetrical distribution of values. Average values of intensity were used to prepare the relation presented in Fig. 5. Intensity was expressed using curing time with the help of polynomial equation. Correlation of the proposed equation is very high and equal to $r=0.9575$. The prediction interval is very narrow (around \pm 0.005 ). 


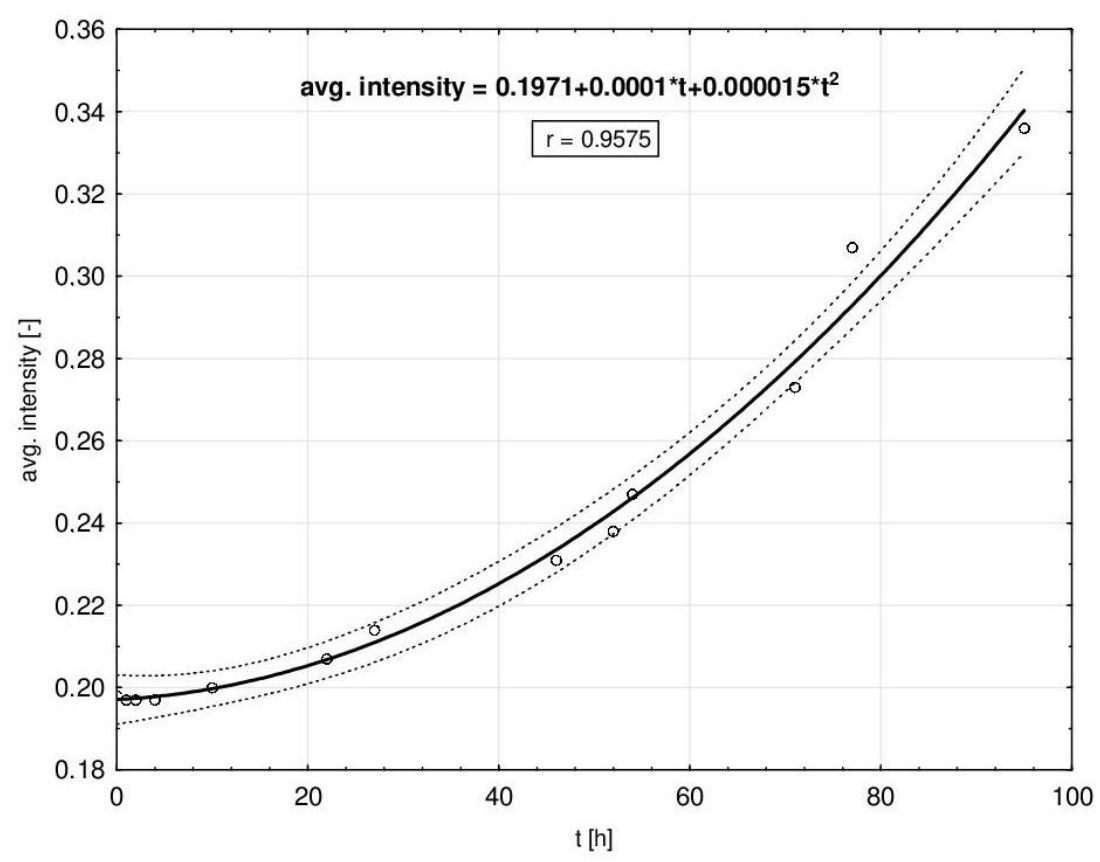

Fig. 5. The curing process of ordinary concrete registered by TLS

Work-package no. 4 was dedicated to field experiments. All previous tests were conducted in lab environment. The aim of the work-package was to assess the feasibility of the discussed TLS testing method in the real outdoor conditions. Two existing historic buildings located in the city of Olsztyn were chosen for remote sensing. Building number 1 was erected at the end of $19^{\text {th }}$ century. It is a classical brick and mortar structure with no plaster. Red ceramic bricks with treated external surface form the façade of the building which is exposed to elements. From the current research programme point of view, the most interesting part of the façade was the area near the broken downpipe. Overflowing rainwater extensively saturates the façade in this area (see Fig. 6 left) on a regular basis. Building number 2 was erected at the end of the $19^{\text {th }}$ century. It was constructed using ceramic bricks. The façade of this building is covered by cement-lime plaster. The examined area is saturated by water due to splash water from the wheels of cars moving down the street along the building and the failure of damp proof course. Water is moving up (capillary movement) saturating larger and larger parts of the wall (see Fig. 6 right) (Katzer \& Kobaka, 2007; Katzer \& Maliszewski, 2007). During the analysis, the clouds of results registered for dry and saturated parts of the walls were compared. The values of intensity were not standardized. Both remote sensing procedures were conducted from the range of $15 \mathrm{~m}$, thus influence of changes of $R$ (less than $0.06 \mathrm{~m}$ ) and of angle $\alpha$ (less than 5 gradians) were insignificant (the calculated change of value of intensity was equal to 0.0025 (Sasidharan, 2016)). For further calculations the value of $C_{2}$ was adopted as constant (see Eq. 3).

In case of building number 1 only ceramic bricks were analysed. The data associated with mortar joints was omitted. A pre-selected dry and saturated areas were analysed (see Fig. 6).

In case of building number 2 also two areas were chosen for the analysis. It should be kept in mind that holes, punctures, cracks, discoloration and other damages of the plaster were influencing the achieved results. The analysis was conducted for the areas as free from these damages as possible. Intensity registered for red ceramic and cement plaster in two states of saturation is presented in Fig. 7. 


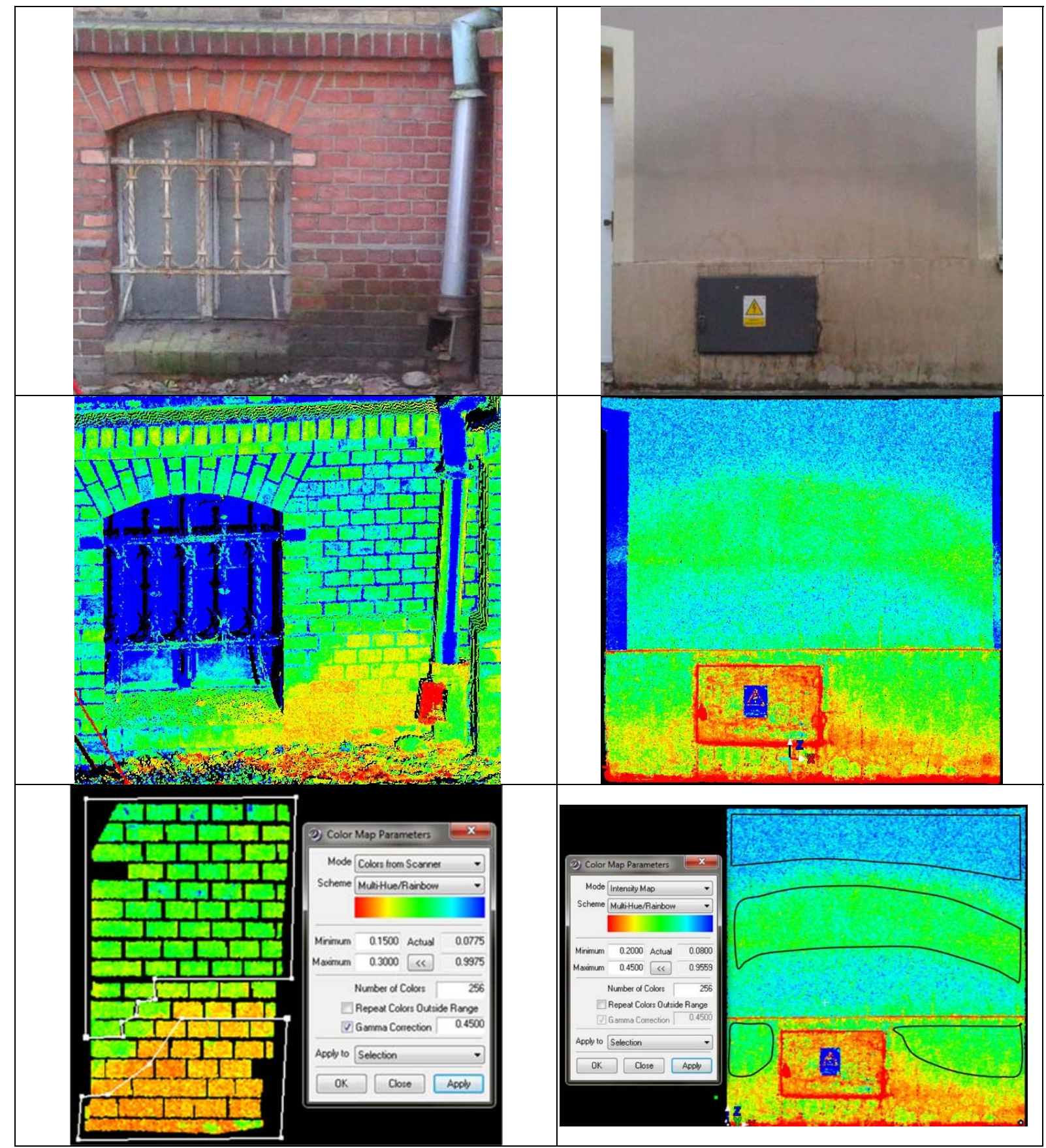

Fig. 6. Examples of water saturated external walls in natural and artificial colours

Based on relations presented in Fig. 7 and statistical data listed in Tab. 2 it can be stated that water saturation significantly influences the quantity of the registered laser signal in both buildings. The least statistically symmetric values were achieved for dry ceramic bricks.

This phenomenon can be associated with a very long lasting saturation resulting in changes of surface roughness and biological activity on the surface (algae and lichens). All these factors change the quantity of the registered laser signal. 


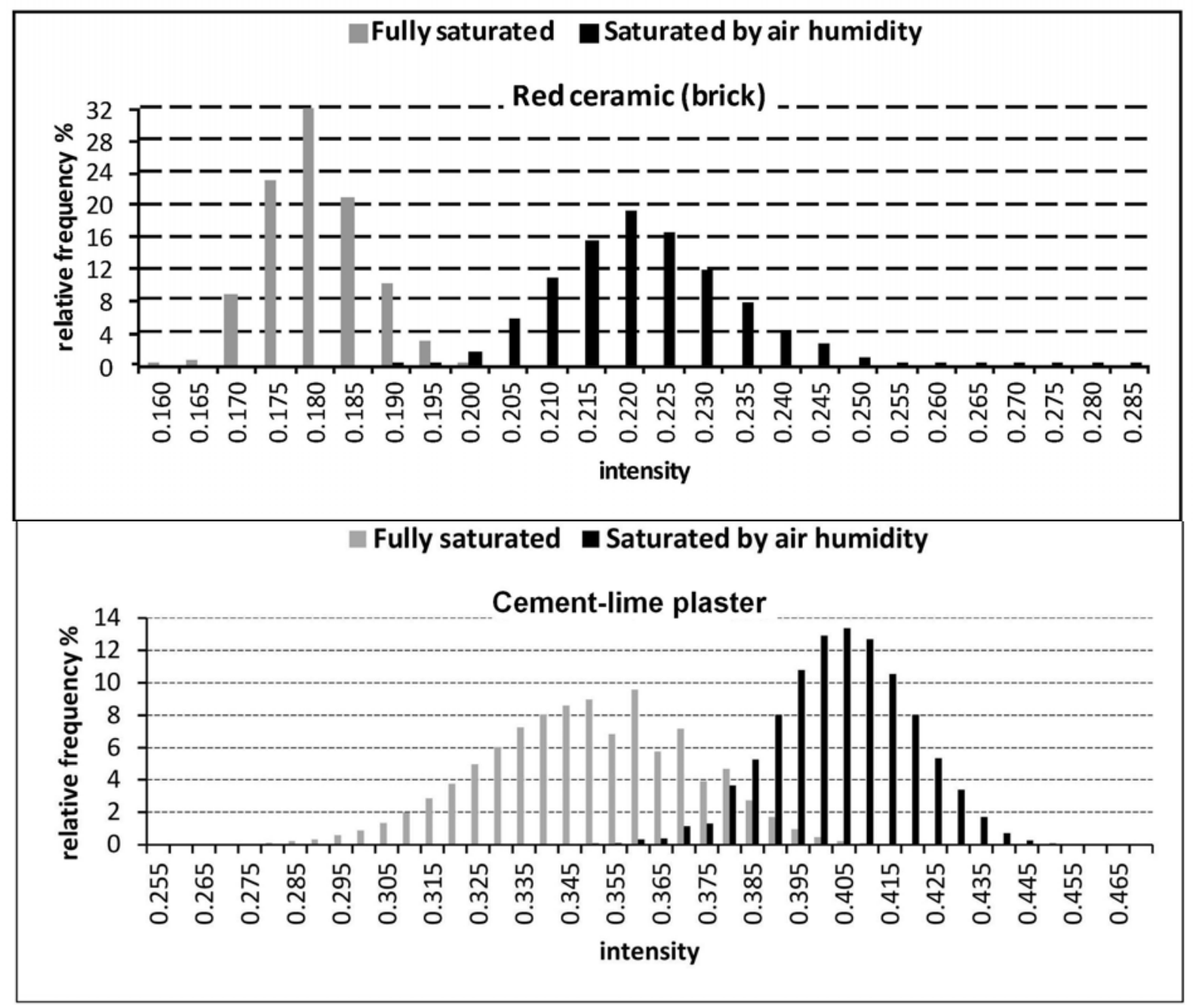

Fig. 7. Intensity registered for red ceramic and cement-lime plaster in two states of saturation

Table 2. Number of tested points $n$ and values of intensity

\begin{tabular}{|c|c|c|c|c|c|c|c|c|c|c|c|c|c|}
\hline \multicolumn{7}{|c|}{ Fully saturated } & \multicolumn{7}{|c|}{ Saturated by air humidity } \\
\hline \multirow{2}{*}{$n$} & \multicolumn{6}{|c|}{ Intensity } & \multirow{2}{*}{$n$} & \multicolumn{6}{|c|}{ Intensity } \\
\hline & $\min$. & $\max$ & avg. & range & median & mode & & $\min$. & $\max$ & avg. & range & median & mode \\
\hline \multicolumn{14}{|c|}{ Red ceramic (brick) } \\
\hline 5481 & 0.160 & 0.197 & 0.178 & 0.037 & 0.178 & 0.177 & 10497 & 0.190 & 0.300 & 0.220 & 0.110 & 0.219 & 0.215 \\
\hline \multicolumn{14}{|c|}{ Cement plaster } \\
\hline 191520 & 0.251 & 0.419 & 0.347 & 0.168 & 0.347 & 0.348 & 109090 & 0.327 & 0.468 & 0.403 & 0.141 & 0.403 & 0.400 \\
\hline
\end{tabular}




\section{Conclusions}

The conducted research programme allows to draw the following conclusions:

- It is possible to follow the process of setting and hardening of ordinary concrete by means of TLS.

- Changes of water saturation of scanned walls influence the quantity of a returning laser signal.

- It is possible to point out saturated areas of walls by interpretation of values of intensity (cloud of results).

- Conducting the same test in the same conditions using different types of TLS apparatuses results in different values of intensity.

- The research should be continued using different scanners, larger number of specimens and other building materials.

\section{References}

Blaskow, R., \& Schneider, D. (2014). Analysis and correction of the dependency between laser scanner intensity values and range. The International Archives of the Photogrammetry, Remote Sensing and Spatial Information Sciences, Volume XL-5, 2014.ISPRS Technical Commission V Symposium, 23 - 25 June, Riva del Garda, Italy, pp. 107-112, DOI:10.5194/isprsarchives-XL-5-107-2014.

Bucksch, A., Lindenbergh, R.C., \& Van Ree, J. (2007). Error budget of terrestrial laserscanning : Influence of the intensity remission on the scan quality, III International Scientific Congress Geo-Siberia, 23-27 April, Novosibirsk, DOI:10.5194/isprsarchives-XL-5-107-2014.

Engström, T., \& Johansson, M. (2009). The use of terrestrial laser scanning in archaeology Evaluation of a Swedish project, with two examples. Jurnal of Nordic Archaeological Science 16, pp. 3-13.

Kaasalainen, S., Jaakkola, A., Kaasalainen, M., Krooks, A., \& Kukko A. (2011). Analysis of Incidence Angle and Distance Effects on Terrestrial Laser Scanner Intensity: Search for Correction Methods. Remote Sens. 3, pp. 2207-2221, DOI:10.3390/rs3102207.

Katzer, J., \& Kobaka, J. (2007). Assessing the strength of gothic brickwork, Restoration of Buildings and Monuments, Vol.13, No 4, 2007, pp. 265275.

Katzer, J., \& Maliszewski, G. (2007). Water Induced Corrosion of Silica Lime Brick Masonry, Restoration of Buildings and Monuments, Vol. 13, No. 2, 2007, pp. 109116.

Kukko, A., Kaasalainen, S., \& Litkey P. (2008). Effect of incidence angle on laser scanner intensity and surface data. Applied Optics Vol. 47, Issue 7, pp. 986-992 DOI:10.1364/AO.47.000986.

Mill, T., Ellmann, A., Uueküla, U., \& Joala V. (2011) Road surface surveying using terrestrial laser scanner and total station technologies. ENVIRONMENTAL ENGINEERING, The 8th International Conference, May 19-20, Vilnius, Lithuania, ISSN 2029-7092 online, pp. 1142-1147.

Oreni, D., Brumana, R., Banfi, F., Bertola, L., Barazzetti, L., Cuca, B., Previtali, M., \& Roncoroni F. (2014). Beyond Crude 3D Models: From Point Clouds to Historical Building Information Modelling via NURBS, Digital Heritage. Progress in Cultural 
Heritage: Documentation, Preservation, and Protection, LNCS 8740, pp. 166-175, 10.1007/978-3-319-13695-0 16.

Park, H.S., Lee, H.M., Adeli, H., \& Lee, I. (2007). New Approach for Health Monitoring of Structures: Terrestrial Laser Scanning, Computer-Aided Civil and Infrastructure Engineering, 22, pp. 19-30, DOI: 10.1111/j.1467-8667.2006.00466.x.

Pfeifer, N., Höfle, B., Briese, C., Rutzinger, M., \& Haring, A. (2008). Analysis of the backscattered energy in terrestrial laser scanning data. The International Archives of the Photogrammetry, Remote Sensing and Spatial Information Sciences. Vol. XXXVII. Part B5. Beijing. pp. 1045-1052 .

Sabatini, R., \& Richardson, M. A., (2010). Airborne Laser Systems Testing and Analysis. RTO-AG-300-V26 NATO Research and Technology Organization, Vol. 26.

Sasidharan, S. (2016). A Normalization scheme for Terrestrial LiDAR Intensity Data by Range and Incidence Angle. International Journal of Emerging Technology and Advanced Engineering, ISSN 2250-2459, Volume 6, Issue 5, May, pp. 322-328.

Suchocki, C. Application of Terrestrial Laser Scanner in Cliff Shores Monitoring. Rocznik Ochrona Środowiska 2009, Vol 11, pp. 715-725.

Suchocki, C., \& Katzer, J., (2016). An example of harnessing Terrestrial Laser Scanner for remote sensing of saturation of chosen building materials. Construction and Building Materials, 122, pp. 400-405. DOI: 10.1016/j.conbuildmat.2016.06.091.

Suchocki, C. Wasilewski \& A. Aksamitauskas C. (2008). Aplication of scanning technology in cliff shores monitoring. The $7^{\text {th }}$ International Conference Environmental Engineering, Volume 3. May 22-23. Vilnius - Lithunia.

Szulwic, J., Tysiąc, P., \&.Wojtowicz, A. (2016). Coastal Cliffs Monitoring and Prediction of Displacements Using Terrestial Laser Scanning. Chapter in book: 2016 Baltic Geodetic Congress (BGC Geomatics). June, pp.61-66, DOI: 10.1109/BGC.Geomatics.2016.20

Tan, K., \& Cheng, X. (2016). Correction of incidence Angle and distance effect on TLS intensity data based on reference targets. Remote Sens, 8, 251, DOI:10.3390/rs8030251.

Tan, K., Cheng, X., Ju, Q., \& Wu, S. (2016). Correction of Mobile TLS Intensity Data for Water Leakage Spots Detection in Metro Tunnels. IEEE Geoscience and Remote Sensing Letters PP(99), September. pp. 1711-1715 DOI: 10.1109/LGRS.2016.2605158.

Van Ree, J.M. 2006. Determination of the precision and reliability parameters of terrestrial laser scanners by creating a practical experiment set-up. Master thesis. 2006.

Voegtle, T., Schwab, I., \& Landes, T. (2008). Influences of different materials on the measurements of a terrestrial laser scanner. The International Archives of the Photogrammetry, Remote Sensing and Spatial Information Sciences. Vol. XXXVII. Part B5. Beijing. pp. 1061-1066.

Zaczek-Peplinska, J., Osińska-Skotak, K., \& Gergont K. (2012). Możliwość wykorzystania zmian intensywności dobicia promienia laserowego do oceny stanu konstrukcji betonowej. Inżynieryjne zastosowania geodezji, Wydawnictwo Politechniki Poznańskiej.

Zygmunt, M., \& Biłka, P. (2014). Analiza możliwości zastosowania naziemnego skaningu laserowego $w$ kontroli i ocenie stanu technicznego budowli piętrzących wode. Acta Sci. Pol., Formatio Circumiectus 13 (3). pp. 115-124 DOI: http://dx.doi.org/10.15576/ASP.FC/2014.13.3.115. 


\section{Authors:}

Ph.D. Czesław Suchocki 1), czeslaw.suchocki@tu.koszalin.pl

D.Sc. Ph.D. Jacek Katzer 1), jacek.katzer@tu.koszalin.pl

M.Sc. Arkadiusz Panuś 2), arkadiusz.panus@uwm.edu.pl

1) Koszalin University of Technology,

Faculty of Civil Engineering Environmental and Geodetic Sciences

2) University of Warmia and Mazury in Olsztyn

Faculty of Geodesy, Geospatial and Civil Engineering 